\title{
Comments on "Biofilms of Candida albicans serotypes A and B differ in their sensitivity to photodynamic therapy"
}

\author{
Mariusz Grinholc
}

Received: 16 April 2014 / Accepted: 2 May 2014 / Published online: 27 May 2014

(C) The Author(s) 2014. This article is published with open access at Springerlink.com

\section{Dear Editor,}

In the April 2014 issue of the online-first article, Rossoni et al. [1] reported that Candida albicans serotype B is more sensitive to photodynamic treatment than serotype A.

As we know, significant variation among particular strains within the same species in response to the photodynamic treatment exists [2]. The differences can reach several logs in survival of viable counts. We have previously shown that taking into consideration the genetic background of microorganisms, i.e., Staphylococcus aureus, within the same closely related strains, assigned as a single epidemic clone, we can identify strains that are highly resistant as well as highly sensitive to photodynamic inactivation (PDI) [3]. Thus, just having a sufficiently large database of strains, one can properly infer about the importance of a particular feature in response to PDI. Unfortunately, as far as I am concerned, study of Rossoni et al. failed to include other than single reference strains of C. albicans. On the basis of single isolates, one must not drew any relevant conclusions.

Moreover, switching the sensitizer can totally reverse the observed response to photodynamic treatment [4]. Consequently, such a general conclusion proposed by the authors stating that $C$. albicans serotype B is more sensitive to photoinactivation is not supported by the evidence, as it requires studies concerning different sensitizing agents. However, the authors have not provided any details about the effectiveness of photoinactivation against both C. albicans serotypes based on other photosensitizers.

Assessing the influence of microorganism's features on susceptibility to photoinactivation is always a complex issue.
Of course, studying one sensitizer and single isolates can give us some information, but the problems in study design should not be ignored, as statistical analysis requires more numerous groups to be compared and to draw relevant conclusions. Those limitations reduce the reliability of presented results.

Open Access This article is distributed under the terms of the Creative Commons Attribution License which permits any use, distribution, and reproduction in any medium, provided the original author(s) and the source are credited.

\section{References}

1. Rossoni RD, Barbosa JO, de Oliveira FE, de Oliveira LD, Jorge AO, Junqueira JC (2014) Biofilms of Candida albicans serotypes A and B differ in their sensitivity to photodynamic therapy. Lasers Med Sci. doi:10.1007/s10103-014-1570-z

2. Grinholc M, Rapacka-Zdonczyk A, Rybak B, Szabados F, Bielawski KP (2014) Multiresistant strains are as susceptible to photodynamic inactivation as their naive counterparts: protoporphyrin IX-mediated photoinactivation reveals differences between methicillin-resistant and methicillin-sensitive Staphylococcus aureus strains. Photomed Laser Surg 32:121-129

3. Rapacka-Zdonczyk A, Larsen AR, Empel J, Patel A, Grinholc M (2014) Association between susceptibility to photodynamic oxidation and the genetic background of Staphylococcus aureus. Eur J Clin Microbiol Infect Dis 33:577-586

4. Nakonieczna J, Grinholc M (2012) Photodynamic inactivation requires innovative approach concerning numerous bacterial isolates and multicomponent sensitizing agents. Photodiagnosis Photodyn Ther 9:359-361
M. Grinholc $(\bowtie)$

Laboratory of Molecular Diagnostics, Department of Biotechnology, Intercollegiate Faculty of Biotechnology, University of Gdansk and Medical University of Gdansk, Kladki 24, 80-822 Gdansk, Poland e-mail: mariusz.grinholc@biotech.ug.edu.pl 